
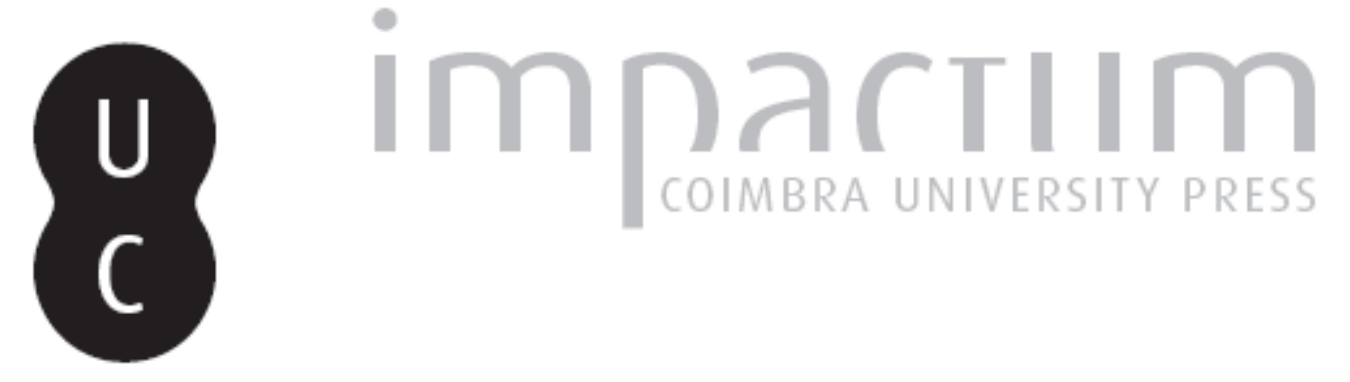

\title{
A primitiva Faculdade de Letras do Porto e a Universidade de Coimbra
}

\author{
Autor(es): $\quad$ Ramos, Luís A. de Oliveira
}

Publicado por: Faculdade de Letras da Universidade de Coimbra, Instituto de História Económica e Social

URL persistente:

URI:http://hdl.handle.net/10316.2/27895

DOI:

DOI:http://dx.doi.org/10.14195/0870-4147_42_4

Accessed : $\quad$ 26-Apr-2023 11:37:37

A navegação consulta e descarregamento dos títulos inseridos nas Bibliotecas Digitais UC Digitalis, UC Pombalina e UC Impactum, pressupõem a aceitação plena e sem reservas dos Termos e Condições de Uso destas Bibliotecas Digitais, disponíveis em https://digitalis.uc.pt/pt-pt/termos.

Conforme exposto nos referidos Termos e Condições de Uso, o descarregamento de títulos de acesso restrito requer uma licença válida de autorização devendo o utilizador aceder ao(s) documento(s) a partir de um endereço de IP da instituição detentora da supramencionada licença.

Ao utilizador é apenas permitido o descarregamento para uso pessoal, pelo que o emprego do(s) título(s) descarregado(s) para outro fim, designadamente comercial, carece de autorização do respetivo autor ou editor da obra.

Na medida em que todas as obras da UC Digitalis se encontram protegidas pelo Código do Direito de Autor e Direitos Conexos e demais legislação aplicável, toda a cópia, parcial ou total, deste documento, nos casos em que é legalmente admitida, deverá conter ou fazer-se acompanhar por este aviso.

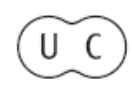





\title{
A primitiva Faculdade de Letras do Porto e a Universidade de Coimbra
}

\author{
Luís A. De Oliveira Ramos \\ Faculdade de Letras da Universidade do Porto \\ luis.a.o.ramos@sapo.pt
}

\section{Resumo:}

A criação da Faculdade de Letras do Porto prende-se à questão académica que marcou a Universidade de Coimbra após a queda da monarquia do Norte. Primeiro, o Governo republicano sujeitou a sindicância quatro professores de Direito apodados de inimigos do regime, processo de que nada resultou. Depois, o ministro Leonardo Coimbra reformou o ensino da Filosofia e nomeou professores da especialidade para a Faculdade de Letras de Coimbra, sem a consultar. Houve reacção do Conselho Escolar apoiada pelos estudantes. Como retaliação, o ministro encerrou tal Faculdade e criou outra na Universidade do Porto, razão de fortíssima reacção universitária e nacional. O Governo seguinte, propôs e obteve do Parlamento a manutenção das duas Faculdades. Para a Porto, o Governo nomeou professores por decreto que, anos depois, se graduaram em Conselho Escolar, conforme a lei permitia, no grau de Doutor. Leonardo e alguns dos colegas, obreiros do movimento democrático e cultural Renascença Portuguesa e da revista Águia que por si justificam a criação da nova Faculdade, defenderam o repto e marcaram pela originalidade. A Escola viveu com dificuldades, contou com opositores anti-democráticos, positivistas e racionalistas, e de sectores da cidade e da sua Universidade. A ditadura extingue-a em 1928.

\section{Palavras chave:}

Universidade do Porto; Faculdade de Letras; Universidade de Coimbra.

\section{Abstract:}

The creation of the Faculty of Letters in Oporto is linked to the academic issue that marked the University of Coimbra after the fall of the so-called 'Monarquia do Norte' (Northern Monarchy). First, the Republican government ordered an enquiry into four law professors told to be enemies of the regime, a process from which nothing came out. Afterwards, Public Instruction Minister Leonardo Coimbra reformed the teaching of Philosophy and appointed professors for the Faculty of Arts of Coimbra without consulting the faculty, which caused a strong reaction from the Faculty Council with support of the students. The minister retaliated by closing that Faculty and creating a new one in the university of Oporto, thus provoking a huge opposition both at university and national level. The following Government proposed and obtained from Parliament the continuation of the two Faculties. For Oporto, the Government appointed teachers by decree who, years later, were awarded the degree of doctor by the School Council, as the law allowed.Leonardo and some of his colleagues, responsible for the democratic and cultural movement named Renascença Portuguesa as well as for the journal Águia - a deed that, for itself, justified the foundation of the new Faculty - faced the challenge and became outstanding for their originality. The Faculty went through difficulties, had anti-democratic, positivist and rationalist opponents, some of them from its own city and university. The Ditadura Nacional (National Dictatorship) terminated it in 1928.

Keywords:

Oporto Faculty of Letters, Leonardo Coimbra, academic conflict, Renascença Portuguesa. 
Segundo a lição de Damião Peres, em termos de história política, a criação, em 1919, da Faculdade de Letras da jovem Universidade do Porto parece resultar da queda precedente da Monarquia do Norte e da atracção que esta terá exercido, na Universidade de Coimbra, sobre prestigiados mestres, factos estes origem da chamada questão académica.

Em Março de 1919, em resposta a variadas críticas que exigiam a eliminação dos quadros do Estado dos inimigos da República, o Governo, chefiado por José Relvas, resolveu, a par de decisões referentes a outros ministérios, a suspensão dos lentes de Direito António de Oliveira Salazar, Fezas Vital, Magalhães Colaço e Carneiro Pacheco, sujeitando-os a uma sindicância para averiguar se deviam ser castigados por actos de "hostilidade ao regime" restaurado, assumidos quer na função docente, quer fora dela. $\mathrm{O}$ facto foi notificado ao reitor, Mendes dos Remédios, oriundo de Letras. Logo depois, para exercer a dita sindicância, que também envolverá Diogo Pacheco de Amorim, de Ciências, e o reitor Mendes dos Remédios, vem a lume a nomeação do juiz Vieira Lisboa, do Supremo Tribunal, para descobrir as "graves acusações políticas" que impendiam sobre os ditos professores.

Ao tomar conhecimento da situação criada em Direito, logo em Março, o reitor demitiu-se e solicitou uma devassa ao seu labor no cargo para que fora oportunamente eleito por sufrágio. Por então, o Governo democrático, agora chefiado por Domingos Pereira, antes ministro da Instrução de José Relvas, nomeia reitor interino, o Dr. Joaquim Coelho de Carvalho, antigo Presidente da Academia das Ciências.

Actuando com rapidez e isenção, um mês depois de indigitado, a 26 de Abril, o juiz Vieira Lisboa concluiu a sindicância, afirmando não ter revelado o processo «a menor cumplicidade de qualquer dos sindicados no último movimento monárquico», nem dele ter resultado prova jurídica de que algum desses professores tivesse praticado actos que, «perante a lei», pudessem considerar-se de «hostilidade à República».

Salazar e Colaço voltaram ao exercício professoral. Fezas Vital e Carneiro Pacheco não o fizeram por estarem ausentes no estrangeiro com bolsas de estudo, refere Damião Peres, cujo texto no Suplemento à História de Portugal, seguimos. ${ }^{1}$

Julgava-se findo o grave dissídio, mas reabriu ao despontar Maio. O ministro da Instrução, Leonardo Coimbra, o gestor do apaziguamento, no final de Abril, procede à reforma dos estudos universitários de Filosofia, matéria em que

1 PERES, Damião - História de Portugal, Suplemento, Porto, Portucalense Editora 1954-1958 , p. 248-249. 
firmara a sua reputação intelectual. Entende vivificá-la com diversas cadeiras de índole científica e filosófica, além de nomear, para outras tantas vagas novas dos quadros das Faculdades de Letras de Lisboa e Coimbra, quatro professores, por simples opção governamental.

Tais circunstâncias determinaram o agravo e a reacção pronta da Faculdade de Letras de Coimbra, não tanto sobre o fundo, naturalmente discutível da reforma, mas pelo facto de se proceder a tais mudanças sem audição da Faculdade, nomeadamente impondo mestres estranhos à instituição por via de nomeação governamental. Daí pedir-se a suspensão dos diplomas. Esta doutrina, constante da representação aprovada no Conselho Escolar de Letras, de 14 de Maio, na presença do reitor Mendes dos Remédios, membro nato desta congregação, e apoiada no dia seguinte por uma representação dos estudantes, implicou imediata resposta governamental.

A 19 do mesmo mês, por Decreto do Governo, ocorreu a substituição de Mendes dos Remédios pelo reitor interino, Coelho de Carvalho, agora definitivo no cargo e, em especial, determinou-se a desanexação da Faculdade de Letras da Universidade de Coimbra, ligando-a à do Porto, assim como a passagem à disponibilidade dos seus professores, a ocupar em cargos culturais. Demais, estabelecia-se na Universidade de Coimbra uma Faculdade Técnica, com Escola de Belas Artes, que jamais entrou em funcionamento ${ }^{2}$.

Assim explodiu, em toda a sua latitude, a questão académica e se erigiu a Faculdade de Letras do Porto, onde o pensador Leonardo Coimbra contava experimentar o seu reformismo filosófico. Se a primeira, a questão académica, aparentemente findou a curto prazo, também não foi longa, muito por causa da sua origem e organização, a vida agitada da Faculdade de Letras do Porto, que não a sua perenidade.

A questão académica no que ela encerra de críticas a Leonardo Coimbra e à sua reforma do ensino superior de Filosofia, de apoio à continuidade da Faculdade de Letras de Coimbra e, por outra parte, de aceitação da Faculdade de Letras do Porto, em paralelo com a de Coimbra, está documentada, desde 1919, graças a uma publicação intitulada A Faculdade de Letras de Coimbra ao País ${ }^{3}$, no essencial aproveitada por Damião Peres. Este historiador anota a solidariedade não só dos estudantes de Coimbra, mas também dos de Lisboa, através de greves e, bem assim, as moções dos Senados universitários de

2 PERES, Damião - História de Portugal, Suplemento, Porto, Portucalense Editora 1954-1958, p. 248-251. Trata-se de uma síntese fundamental que seguimos ao longo da análise da questão académica.

3 A Faculdade de Letras de Coimbra ao País, Coimbra, 1919. 
Coimbra e do Porto. Aqui, embora satisfeitos com a instituição da nova Faculdade de Letras, a moção dos lentes senadores defende a permanência da Faculdade de Letras na velha Universidade. No mesmo sentido, em prol de Coimbra, surgiram documentos de professores, grupos de docentes e políticos, alguns deles fora de dúvida republicanos. A exploração do teor das posições ou dos discursos parlamentares ocupa largo espaço na recente dissertação de doutoramento sobre Newton de Macedo. ${ }^{4}$

Em todas estas tomadas de posição, sobreleva, no essencial, o choque entre monárquicos e a política de educação da República, por um lado, e, por outro, os conimbricenses apodados, alguns, de reaccionários, até pela origem da Faculdade de Letras de Coimbra, onde um número expressivo de professores, alguns republicanos, provinha da antiga Faculdade de Teologia. Havia, nas hostes conimbricenses professores doutorados ou já efectivos, homens conhecidos da política, incluindo republicanos, conservadores, monárquicos, calados na defesa da respectiva cátedra. Mas nenhum dos mestres discutidos e ex. lentes de Teologia (que só um e bem republicano esquece, a saber, Porfírio António da Silva, que falecera em 1918) é professor por concurso, e nenhum possui doutoramento em História, posto o tivessem feito em Teologia. A sua situação resultava da nomeação pelo Governo Provisório e de votações doutorais do Conselho Escolar de Letras ${ }^{5}$.

Doutorados em Filosofia e em História, com defesa de tese, são, em 1919, os prestigiados Doutores Joaquim de Carvalho e Manuel Gonçalves Cerejeira estrénuo defensor da permanência das Letras em Coimbra, o primeiro, a par, já sabemos, de muitos outros republicanos da universidade da cidade e do País, com relevo maior para o Doutor Teófilo Braga. Cerejeira e Carvalho são nomeados professores ordinários de Letras nesse ano de 1919, pelo mesmo decreto que coloca no Porto, em idêntica categoria, Leonardo Coimbra.

Marcada pelo sectarismo e nalguns casos pelo entusiasmo e pela razoabilidade, a discussão da questão académica animou o Parlamento sob o ministério de Domingos Pereira (também ele bacharel em Teologia), sobraçando a pasta da Instrução, Leonardo Coimbra, activo nos debates e, bem assim, no Governo seguinte de Sá Cardoso, com Joaquim de Oliveira no ministério da Instrução ${ }^{6}$.

4 Sobre Newton de Macedo e a antiga Faculdade em geral ver: BAPTISTA, Pedro A pluralidade na escola portuense de Filosofia. Lisboa, Imprensa Nacional Casa da Moeda, 2010.

5 RODRIGUES, Manuel Augusto - Memoria Professorum Universitatis Conimbrigensis, 1772-1937, vol. II, Coimbra, Arquivo da Universidade, 1992, p. 63.

6 RAMOS, Luís A. de Oliveira - "Vultos Republicanos". In: Boletim Cultural Vila Verde, 6 (2011),p. 140, 141 , 143, 147. Consulte-se ainda: NOGUEIRA, Franco - Salazar: a mocidade e os princípios, Coimbra, Atlântida Editora, p. 189, 199, 213. 
Dada a dimensão da crise, dos vitupérios e dos elogios que se cruzavam por causa do fecho da Faculdade de Letras de Coimbra, fala-se da resolução do problema criado pelo Governo nas arenas parlamentares. A ideia vem a ser perfilhada pelo indigitado ministro Joaquim de Oliveira, (deputado desde a Constituinte, bacharel muito distinto em Teologia e Direito por Coimbra e até apontado para uma eventual docência na Faculdade de Direito, quando das sindicâncias) e surge inscrita de forma sintética no prolixo e ambicioso programa do Governo presidido pelo Major Sá Cardoso que defende a prevalência das duas Faculdades no Porto e em Coimbra. Diz-se no dito Programa: «Propõe-se o Ministério da Instrução, se o Parlamento assim o entender, manter uma Faculdade de Letras em Coimbra, sem prejuízo da já estabelecida no Porto.»

Esta Escola foi, em definitivo, fundada e veio a funcionar com um quadro de disciplinas e secções análogas às congéneres de Lisboa e Coimbra, começando a laborar em 1919-1920, alcançada a aprovação parlamentar. Quanto ao ensino da Filosofia, esse ficou de ser reavaliado.

Posto a funcionar o programa do Governo Sá Cardoso, a resolução da questão académica é remetida para o Parlamento, onde o ministro da Instrução Joaquim de Oliveira defende a solução de compromisso que se antevira, a saber, a existência de duas Faculdades, uma em Coimbra, outra no Porto, em confronto aceso com os críticos e os defensores de Leonardo, dentro do espírito apaziguador desejado pelo Governo.

Newton de Macedo e Lúcio Pinheiro dos Santos, ambos professores do Liceu, com estágios no estrangeiro e obra prometedora, indigitados para as duas vagas de Filosofia que Leonardo Coimbra esperava pôr a funcionar em Coimbra, são colocados no Porto, no grupo de Leonardo, também ele nomeado professor e director da nova Faculdade, depois de sair do Governo, pelo novo ministro da Instrução, Joaquim de Oliveira.

Por ordem do executivo, em História fica Damião Peres, já então e desde os tempos de estudante, figura de prestígio, juvenil reitor do Liceu do Funchal e pessoa grada no ministério da Instrução juntamente com o militar e personalidade jornalística, Homem Cristo, temível polemista e Augusto Ferreira Nobre, familiar do reitor da Universidade do Porto, do mesmo apelido.

Para Germânicas, os nomeados são Luís Cardim e Ângelo Ribeiro. Em Clássicas ficam Canuto Soares e, posteriormente, Francisco Torrinha. Hernâni Cidade, um nome que começa a impor-se, e Teixeira Rego, brilhante autodidacta, compaginam com o esclarecido António Luís Gomes, recém-licenciado em Direito e filho do antigo membro do Governo Provisório, nas Românicas. Indigitado para Ciências Geográficas será Mendes Correia, médico e docente da Faculdade de Ciências, que se há-de impor como 
antropólogo. Rege a cadeira anexa de Estética e História de Arte Aarão de Lacerda (só contratado em 1922), professor de Belas Artes, filho de um lente da Politécnica, jurista que se formará em História e vai pontificar nas Faculdades do Porto e de Coimbra.

A média etária deste conjunto queda-se nos trinta e poucos anos, o único quase sexagenário é Homem Cristo, António Luís Gomes possui vinte e um; Canuto Soares, Newton de Macedo estão com vinte e cinco anos em 1919; Damião Peres, Mendes Correia e Hernâni Cidade têm, respectivamente, trinta, trinta e um e trinta e dois anos.

Dados analisados referentes a uma amostra de quinze professores, diz que nove vieram ao mundo a norte do Vouga, no Portugal atlântico, um nasceu em Aveiro, outro em Famalicão, sete no distrito do Porto. A região de Lisboa foi berço de três. O Alentejo era a província de Hernâni Cidade. Das Ilhas Adjacentes vieram Canuto Soares e Ângelo Ribeiro, naturais, respectivamente, do Funchal e de Angra.

Se olharmos do ponto de vista social este conjunto de professores, verificamos que se trata, em regra, de gente da classe média, com raiz plebeia. Entre eles, descobrimos um grupo de filhos família com mérito intelectual. Volto a referir Augusto Ferreira Nobre, Aarão de Lacerda, António Luís Gomes e o cunhado de Mendes Correia, Magalhães Basto, a seu tempo contratado como assistente. Entre os professores o predomínio situa-se nos formados em Letras por Lisboa. Há também um Politécnico da capital, outro do Porto e um teólogo, a par de um médico da Escola portuense (Mendes Correia) e um graduado da Escola do Exército, Homem Cristo. De Direito provinham António Luís Gomes, Magalhães Basto e Aarão de Lacerda. Os dois últimos tiraram ulteriormente o curso de Histórico-Geográficas em Coimbra. Carente de estudos universitários, mas intelectual e professor da melhor estirpe, alça-se Teixeira Rego, discípulo de Sampaio Bruno, cujas provas que o elevaram ao Ensino Superior residem nos seus ensaios e artigos publicados, vários, na revista Águia.

Conforme voto legal, realizado em anos sucessivos, no Conselho Escolar da nova Faculdade, ignorando o sistema de provas públicas, por virtude da qualidade demonstrada no serviço universitário, foram galardoados com o grau de Doutor, os seguintes professores ordinários: primeiro, o filósofo Leonardo Coimbra em 1921, em 1922, Damião Peres, de História, Teixeira Rego, de Românicas, Newton de Macedo, de Filosofia, Mendes Correia, de Geografia. Em 1926 receberam, pelo mesmo processo, a borla e capelo, Hernâni Cidade, de Românicas, Luís Cardim e Ângelo Ribeiro, de Germânicas, Aarão de Lacerda, de História da Arte, Francisco Torrinha e Canuto Soares, de Clássicas 
e Augusto Ferreira Nobre, de História. Canuto e Nobre receberam, por último, o doutoramento, como se về .

Para bem entender este aspecto da antiga Faculdade de Letras do Porto, urge ter presente que a «Lei 616 de 19 de Junho de 1916, no seu art. ${ }^{\circ} 16$, reconhecia às Faculdades o direito de conferirem o grau de Doutor aos professores ordinários bem como aos extraordinários com três anos de serviço que o não possuíssem», ensina Marcello Caetano, explicando que o Decreto $n^{\circ} 4554$, de 6 de Julho de 1918, que configura o Novo Estatuto Universitário, pelo «art. ${ }^{\circ} 96, \S$ único, mantinha-se o direito das Faculdades de conferir o grau de Doutor aos professores ordinários que o não possuíssem, bem como «a individualidades eminentes dignas dessa distinção ${ }^{8} »$.

Se uma boa parte destes professores era colega de Leonardo Coimbra no Liceu Gil Vicente ou com ele trabalhara, um número bem significativo integrava o núcleo que, antes e depois da criação da Faculdade, pontificara no movimento portuense da Renascença Portuguesa ou na Revista Águia, a começar por Leonardo. Pode dizer-se, como se escreveu, que o filósofo aproveitou a passagem pelo ministério para criar a Faculdade de Letras do Porto.

Todavia a Escola tem uma raiz portuense e beneficia do ambiente criado na cidade durante o primeiro quartel do século, quando se afirma a República, conforme sugere Salgado Júnior, o primeiro Doutor em Românicas, aluno da primitiva Faculdade. Ao falar do Porto culto, vinca a conexão, já de Leonardo Coimbra, já da Faculdade com o movimento da Renascença Portuguesa e a revista Águia, que vicejaram, no Porto e são testemunhos da vitalidade cultural do período republicano e, bem assim, da pujança cultural daquela cidade, por via dessas realizações, entre si conexas e de dimensão nacional.

Considerando o significado cultural da Renascença e directamente a sua articulação com a Faculdade de Letras, Salgado Júnior explica que a Renascença ultrapassa o autodidatismo e o trabalho isolado do Porto culto anterior e irrompe como «a primeira afirmação de um movimento cultural caracterizado», subsequente à queda da monarquia, expressando novas esperanças e uma renovação a conceber no âmbito do novo regime político.

Trata-se de um processo que a urbe bem entendeu a ponto de se entusiasmar com a ideia de o sustentar. A quantidade de sócios que se inscreveram assegurou as suas finanças, a quantidade de alunos que frequentou os cursos aí realizados

7 RAMOS, Luís A. de Oliveira - Sob o signo das Luzes, Lisboa, Imprensa Nacional Casa da Moeda, 1988, p. 209-221.

8 CAETANO, Marcello - Apontamentos para a História da Faculdade de Direito de Lisboa, Universidade, 1961, p. 45. 
serviu de aval à sua oportunidade e ao seu futuro. $\mathrm{O}$ facto de se esgotarem os seus livros revela a atenção pela valia dos assuntos abordados. Ainda na opinião de Salgado Júnior, pertence então ao Porto uma função catalítica, ressurgindo no burgo uma evidente consciência literária que tornou urgente a criação de uma Faculdade de Letras, Faculdade que deu continuidade à Renascença.

E deu continuidade visto que, um bom número de professores e alunos da Faculdade pertenceu ou veio a pertencer ao movimento; porque essa plêiade estimulou tertúlias, jornais, cursos e conferências na cidade. Demais, insistimos nós, a Faculdade de Letras fundada por Leonardo Coimbra faz parte da estirpe republicana e democrática cujo espírito variado caracterizou e veio a lume numa cidade com as características do Porto. Configura uma urbe com nova fisionomia portuária, já vivificada pelos caminhos de ferro, cunhada pelo labor de bancos e companhias, pelo afã de fábricas, armazéns e lojas de comércio, ponto de encontro da actividade económica, já da bacia do Douro, já do Entre-Douro e Minho, já do Além Douro, onde a criatividade nos negócios serve de base à ascensão da classe média. De resto, no Porto levedara a revolta republicana de 31 de Janeiro, o que, para Basílio Teles demonstrara a existência em Portugal de «homens capazes de fazerem sacrifícios por uma ideia».

E na cidade sentem-se as reivindicações do movimento operário e, bem assim, o teor de ideias socialistas, anarquistas e comunistas, posto que em sectores e núcleos de pequena dimensão na sociedade local.

Noutra dimensão e no mesmo período, a cidade viveu um processo de vitalização clerical e nela habitaram elementos nacionalistas e da corrente monárquica mais tradicional, depois ligados ao integralismo lusitano de sentido anti-democrático e ao Estado Novo9.

Independentemente das posições deste ou daquele docente, a Universidade criada em 1911, ao despontar o regime democrático, ainda que sucessora da Academia Politécnica e da Escola Médico-Cirúrgica, alcança a Faculdade Técnica em 1915 (Engenharia em 1926) e ostenta sinais de pujança, e de capacidade para responder às urgências mais evidentes da comunidade, formando médicos, engenheiros, professores de Ciências, farmacêuticos, num tecido social onde também floresce o ensino e a actividade artística, quer oficial, quer particular. Sector a não esquecer resulta do crescimento do magistério liceal, dada a capacidade de muitos servidores seus.

Finalmente, com a Renascença, dada a mobilização que provocou, a cidade descobre, no âmbito privado, a relevância das ciências humanas, que, a título individual, não institucionalizado, vultos de relevo vinham testemunhando

\footnotetext{
9 RAMOS, Sob o Signo..., p. 215-221.
} 
através de jornais e livros. Ora, como Jaime Cortesão inculcou, no plano cívico, pedagógico e de pesquisa, a Renascença quadra com evidentes necessidades que no Porto estavam à vista. A este respeito deve ainda falar-se da Universidade popular que o mesmo Cortesão dinamizou no Porto a meio da segunda década de novecentos. Por maioria de razão, dado o seu carácter precursor, registe-se o funcionamento no burgo, durante a propaganda republicana, a partir de 1904, da Universidade Livre, a primeira de Portugal, erigida pelo comité académico e operário, ligado a estudantes e lentes de Medicina e da Academia Politécnica, mas também, a associações obreiras, dinamizada pelo estudante médico, Manuel de Oliveira, depois clínico reputado, na República deputado à Constituinte, Senador e Governador Civil do Porto ${ }^{10}$.

Muito controversa por ter um corpo de professores de nomeação governamental, que sucessivamente, em Conselho Escolar, se promoveram a doutores, a primitiva Faculdade de Letras que o Governo ditatorial fecha em 1928 e funciona até 1931, para os alunos matriculados poderem concluir as suas licenciaturas, deixou recordação perene nos seus antigos alunos, que se ufanavam do saber aí adquirido e da qualidade e originalidade do ensino dos seus mestres, alguns dos quais deixaram marca no estudo da sua especialidade em Portugal.

Os seus nomes, esses já os indicamos. Alguns deles ainda hoje são referências nas matérias antes ensinadas e nas respectivas bibliografias. O pensamento de alguns motivou e está a motivar dissertações de mestrado e de doutoramento.

De todos, o mais famoso e objecto de sucessiva investigação, com um grupo conhecido e reputado de discípulos, é Leonardo Coimbra, antigo professor liceal de Matemática, que depois do fecho da Faculdade voltou para esse grau de ensino. Escreveu numerosos volumes sobre o criacionismo e diversas matérias de actualidade, nomeadamente como pedagogo e como crítico na área do pensamento. Além de criar, dirigir e alimentar o magistério de Filosofia na Faculdade de Letras do Porto, distinguiu-se pela originalidade com que nas aulas, em tertúlias e passeios influenciava e debatia com os seus alunos. Revelou-se também no Parlamento e na cátedra pela oratória, onde a racionalidade da formação científica combina com a imaginação e o sentimento na pesquisa gnoseológica e metafísica, tão increpada por positivistas, racionalistas, etc.. Um dos meus professores em Lisboa, explicou-me que ele criara uma pecha metafísica no pensamento em Portugal!

Outro professor de eleição, Francisco Newton de Macedo, fizera estágio liceal na Escola Normal Superior de Lisboa, e distinguiu-se já pela capacidade moderna de ensinar, atento que era à natureza de cada aluno, já pelo rigor de um

${ }^{10}$ RAMOS, Vultos..., p. 140-143. 
ideário próprio, fecundo a estudar, à luz da razão, os problemas filosóficos e o desenvolvimento da Psicologia Experimental, conforme atesta a sua produção livresca e o seu magistério.

Como Newton de Macedo, Lúcio Pinheiro da Silva foi nomeado para as novas vagas da Faculdade de Coimbra, criadas pelo ministro da Instrução, Leonardo Coimbra, que não foram desejadas pela respectiva Universidade, tal como a reforma dos estudos filosóficos, e acabou por ser indigitado professor para a nova Faculdade do Porto. Não o aceitou de bom grado, dispersou-se pela política e administração colonial e embarcou para o Brasil, onde fez uma carreira honrosa, graças ao que aprendera na Escola Politécnica de Lisboa, no Colégio de França e na Sorbonne, onde estagiara antes de 1919, altura em que fruía de aura no Liceu Gil Vicente de Lisboa. Nunca ensinou no Porto.

O nome mais conhecido e reputado do grupo de História pertence a Damião Peres que se sagrou como director e redactor da História de Portugal, com oito volumes e um Suplemento, este da sua exclusiva responsabilidade, cujos colaboradores escolheu com mestria entre os especialistas disponíveis. Deve-se-lhe, conforme a metodologia escolhida, a obra de referência, História dos Descobrimentos Portugueses, a par de muitos outros trabalhos em que primam Como Nasceu Portugal e os estudos sobre Numismática. Importa acentuar que alguns dos seus livros principais encerram matérias pela primeira vez ensaiadas na Faculdade de Letras do Porto.

Homem Cristo não marcou posição como historiador e na sua biografia, às vezes, nem se fala da sua passagem pela Escola do Porto. Serve de exemplo a Grande Enciclopédia Portuguesa e Brasileira. De Augusto Nobre, sabe-se que foi um professor interessado, usando bibliografia estrangeira actualizada, em cadeiras de História Geral.

No que respeita a Filologia Românica, impuseram-se na regência de várias cadeiras, Teixeira Rego, autodidacta de talento e Hernâni Cidade, mestre de grande probidade científica e gosto pela labuta intelectual, que veio a escrever obras fundamentais no século XX. É o caso das Lições de Literatura e Cultura Portuguesa, A Literatura autonomista sobre os Filipes, A Literatura portuguesa e a expansão Ultramarina, os volumes sobre José Anastácio da Cunha (tendo apensas poesias inéditas), sobre Luís de Camões e tantos outros. Também alguns deles, iniciados nas suas lições portuenses. De António Luís Gomes, registe-se que optou pelo Direito e se evidenciou nas Finanças. Do mesmo modo, a sua condição de Professor da Faculdade de Letras falta nos dados da sua biografia, na já citada Grande Enciclopédia.

Em Geografia, além do mais, Mendes Correia deu conta dos seus estudos antropológicos, em parte constantes do voluminho Raízes de Portugal. 
Foi nessa área e como professor da Faculdade de Ciências do Porto, Presidente do Município local, político e director da Escola Superior Colonial que ficaram marcas das suas omnímodas capacidades.

Na Filologia Germânica descobrimos um político republicano, Ângelo Ribeiro, professor do Liceu e esperança da sua geração, que mais tarde se transferiu para a secção de História e um seu colega, de indiscutível mérito, com obra conhecida e formação acepilhada na Inglaterra e na Alemanha, Luís Cardim.

Resta falar de Aarão de Lacerda, professor de História da Arte nas Belas Artes, do Porto e depois na novel Faculdade e na Faculdade de Letras de Coimbra, para onde transitou. A ele se deve, entre diversíssimos artigos e ensaios, a História da Arte em Portugal, de que redigiu, antes da morte, os dois primeiros volumes e que continua a ser de consulta.

Artur de Magalhães Basto entrou como assistente de Geografia, passou para História e veio a ser o principal especialista da História Portuense no seu tempo. Concebeu, dirigiu e escreveu com Damião Peres e outros autores a História da Cidade do Porto, em três volumes, em muitos aspectos, apesar de envelhecida e com colaboração desigual, obra de consulta.

$\mathrm{Na}$ Filologia Clássica ensinaram dois professores competentes oriundos dos liceus, Urbano Canuto Soares e Francisco Torrinha. O primeiro produziu, enquanto universitário portuense, obra vária e honrou o magistério na Universidade de São Paulo, depois de o fazer no Porto. Trabalhos importantes vieram à luz quando ensinava na nova Faculdade. Torrinha impôs-se como dicionarista, gramático e ensaísta.

A Faculdade de Letras do Porto, sempre criticada por positivistas e racionalistas, adversários de Leonardo, e hostilizada pelo facto de possuir um corpo de professores ordinários nomeados pelo Governo e de ter elevado, conforme a lei permitia, cada um dos seus membros ao grau de doutor pelo respectivo Conselho Escolar, de que todos os mestres beneficiados faziam parte, funcionou com notórias dificuldades económicas apanágio do País, em instalações impróprias, agravada a sua situação pelo republicanismo dos professores, pelas desavenças entre membros do corpo docente, pela lembrança de que inicialmente surgira em detrimento da Faculdade de Letras de Coimbra, por obra política de Leonardo. Todavia, começou a afirmar-se pela labuta e dedicação dos seus professores e pela qualidade dos alunos que sucessivamente a procuraram. $\mathrm{O}$ facto não impediu que António Sérgio, quando passou pela pasta da Instrução, pensasse no seu fecho. De resto, a cidade, os estudantes e os professores de outras escolas da Universidade olharam sem interesse e compreensão, às vezes com desprezo, a existência de uma Faculdade de Letras. 
Em 1927, na vigência de Governo ditatorial, começou a falar-se na sua extinção, evocando as dificuldades materiais da Nação, ao mesmo tempo que se dizia o mesmo da Faculdade de Direito de Lisboa, onde pontificara, desde a fundação até ser demitido em 1926, o corifeu da República, Afonso Costa. Todavia, nesta Escola dominou o princípio de recrutar os seus professores por concurso público e independentemente das suas opções partidárias. Além disso, para ela pediram transferência numerosos lentes da Faculdade de Direito de Coimbra, alguns de feição monárquica, independentemente da sua competência que, nos casos sabidos, existia.

Apesar do apoio que no Porto a Faculdade de Letras fruía no Senado da Universidade, não obstante as diligências em comum assumidas pelos professores da Faculdade de Direito e pela Reitoria de Lisboa junto do Ministério, salientando, em representação, os serviços prestados e a indispensabilidade de uma Escola jurídica do género na capital de Portugal, a ideia foi por diante, quando o ministro da Instrução era Alfredo de Magalhães, reitor e professor de Medicina da Universidade do Porto, que não muito antes, subscrevera, no respectivo Senado, uma moção a favor das Letras ${ }^{11}$.

De facto, «o Decreto-Lei n ${ }^{\circ}$ 15365, de 12 de Abril de 1928, extinguia, sem qualquer fundamentação, juntamente com a Faculdade de Letras da Universidade do Porto e a Faculdade de Farmácia da Universidade de Coimbra, a Faculdade de Direito da Universidade de Lisboa» ${ }^{12}$.

Não faltaram os apoios de estudantes e professores à Faculdade de Direito de Lisboa, «entre os quais o da Faculdade de Direito de Coimbra, tanto mais significativa e apreciada quanto é certo que ao zelo excessivo de alguns dos seus admiradores se atribuía a extinção da Escola de Lisboa», explica Marcello Caetano. Graças à intervenção de lentes influentes de Lisboa, onde sobressai Carneiro Pacheco, transferido de Coimbra e à boa compreensão de Duarte Pacheco, que substituíra Alfredo de Magalhães no Ministério da Instrução, decidiu este esclarecido governante restabelecer definitivamente a Faculdade de Direito da capital.

No Porto, verificou-se uma clara tomada de posição do Vice-Reitor em exercício Sousa Pinto, do Senado Universitário e dos novos reitores, o mesmo Sousa Pinto e o desembargador Alberto Plácido, a favor da permanência da Faculdade de Letras, a cujo desaparecimento não estariam ausentes, directa ou indirectamente, os chamados, admiradores de Coimbra. Será assim? O ministro

${ }^{11}$ SANTOS, Cândido - Universidade do Porto: raízes e memória da instituição, Porto, Universidade, s.d., p. 298-302.

${ }^{12}$ CAETANO, Marcello - ob. cit., 91. 
Alfredo de Magalhães sempre se disse impossibilitado (porque forças, não se sabe!), de mudar o que estava decidido pelo Governo.

Quanto à Faculdade de Farmácia de Coimbra, sabe-se que vegetou durante tempos e reabriu com três anos sem licenciatura, e só licenciatura autorizada em 1968.

Como se disse, a Faculdade de Letras do Porto continuou a funcionar até 1931, em ordem à finalização dos cursos dos estudantes matriculados.

Nos últimos anos surgiu a licenciatura de Ciências Histórico-Filosóficas e a Geografia tornou-se autónoma como nas Escolas análogas. Prestaram provas de doutoramento os Doutores Salgado Júnior, em Românicas e Agostinho da Silva em Clássicas, que se tinham licenciado, com muito mérito, respectivamente, em 1926 e 1928.

Nas últimas vagas de alunos, distinguiram-se, por exemplo, Álvaro Ribeiro, Delfim Santos, Casais Monteiro, entre outros.

Hernâni Cidade e Damião Peres, como sabemos, vão tornar-se Professores Catedráticos das Faculdades de Letras de Lisboa e Coimbra. Aarão de Lacerda passará para a cadeira anexa de História de Arte, em Coimbra, escola que também convidou Francisco Torrinha para uma cátedra de Clássicas e onde Armando de Lacerda desenvolveu o magistério de Fonética. Canuto Soares pertencerá aos quadros da Universidade de S. Paulo, no Brasil. Os antigos alunos Delfim Santos e Torquato Soares ascendaram à cátedra, respectivamente, em Lisboa e em Coimbra. Agostinho da Silva e Casais Monteiro, na Universidade de Brasília e S. Paulo, respectivamente.

Mas há que acrescentar algumas observações importantes. Desde o princípio, a Faculdade, conforme as disponibilidades, organizou uma biblioteca, parte da qual constitui o fundo antigo da que hoje existe, onde há raridades. Outro interesse básico centrou-se na criação de uma revista, destacando-se a Revista de Estudos Históricos. Nela colaboraram professores das várias secções com artigos originais. Não se descurou a organização de museus.

No Conselho Escolar, muito cedo despontou uma forte corrente, encabeçada por Mendes Correia e Newton de Macedo, que defendia a escolha de professores por concurso, teoria que, pelo menos, se aplicou aos assistentes e aos professores de línguas ${ }^{13}$.

Por outro lado, vinque-se, o Ministro Duarte Pacheco pessoalmente chegou a admitir a continuidade da Faculdade de Letras do Porto. Atestam-no as

${ }^{13}$ PINA, Luís - "Faculdade de Letras do Porto: breve história", In: Cale: Revista da Faculdade de Letras do Porto, 1, (1966), p. 81, 131, 133. 
actas do respectivo Conselho Escolar. O Professor Luís de Pina ${ }^{14}$, ao estudar a antiga Faculdade de Letras, sublinha, com boas fontes e conhecimento pessoal, a falta de interesse da cidade, das suas instituições maiores, das suas escolas superiores, a par da má língua individual deste ou daquele professor, enfim, da sua gente, por essa Escola.

Finalmente, no Porto, como em Coimbra e em Lisboa, funcionaram as licenciaturas em Filologia Clássica, Românica/Germânica, Ciências Histórico-Geográficas, Filosofia e, por último, as Ciências Históricas e Filosóficas e, autonomamente, a Geografia, cursos em que deixaram nome um grupo de notáveis alunos, professores do Liceu, das Escolas Técnicas e do Magistério Primário, bem como as individualidades universitárias que referimos. O tempo fez jus aos professores e alunos que em curtos anos, cunharam a Primitiva Faculdade de Letras e daí que a actual Faculdade se apresente na continuidade dessa Escola, não apenas pelo nome, mas pelo esforço de bem servir a região e o país, a pesquisa e a inventiva científica, a par das suas congéneres.

Para ter uma ideia precisa da função e qualidade das Faculdades de Letras em Portugal, agora novamente parcelarmente discutidas, valioso seria proceder ao estudo comparado das três primeiras, desde o Curso Superior de Letras, até à explosão universitária iniciada nos finais do século XX, quando estão ultrapassadas muitas das quezílias de outrora e se impõe a reflexão e a inovação no campo das ciências humanas e sociais.

${ }^{14}$ PINA, Luís - ob. cit., p. 138. 